hearing loss within his own particular sphere of interest.

The result is a unique publication which looks at the subject from several angles covering such topics as deafness of genetic origin, iatrogenic deafness, occupational hearing loss and the effect of noise on the cochlear structures, the audiological investigation of sensorineural hearing loss, the labyrinthine fluids and their importance in the pathogenesis of sensorineural deafness and electrophysiological studies of the cochlea. All the individual contributions are of a high standard, but it is the discussion following each which sets this book apart. It is the aim of the Ciba Foundation to create an environment which encourages the uninhibited interchange of ideas, and the participants of this symposium have obviously reacted with enthusiasm. No ambiguity has been left unchallenged, nor any fruitful avenue of discussion left unexplored.

At the end, Ashley comments, "If we are to regard the tackling of sensorineural hearing loss as the Everest of deafness, it is abundantly clear at the moment that we are only struggling in the foothills." Although it may be true that the perceptive deaf seeking relief from their affliction will find little comfort in this book, other readers will gain considerable encouragement from the discussions bearing on the equally important topic of deafness prevention. In focusing such a diversity of interests on the problem of sensorineural hearing loss, this book sets a precedent which it would be profitable for others to follow. J. D. HooD

\section{Inside the Rumen}

Physiology of Digestion and Metabolism in the Ruminant. Edited by A. T. Phillipson. (Proceedings of the Third International Symposium, Cambridge, England, August 1969.) Pp. $\mathrm{x}+636$. (Oriel: Newcastle upon Tyne, October 1970.) $120 s$.

THE particular characteristics of the rumen, its microbial population and the host animal have led to the development of a unique area of study. A variety of distinct academic disciplines have contributed to this field of endeavour; biochemistry, physiology, microbiology, nutrition, anatomy and others. The focus of attention on the subject stems to a large extent from the work of the late Sir Joseph Barcroft and his colleagues at the Agricultural Research Council Unit of Animal Physiology in Cambridge during the period 1940 to 1945 . It was therefore particularly appropriate that a symposium dealing with this subject should have been held in Cambridge in 1969 and that the proceedings should be edited by Professor A. T. Phillipson, a prominent member of the original unit and now something of a father figure to those concerned with the rumen.

The proceedings of the symposium constitute a comprehensive and up to date statement of knowledge in this particular and integrated field of study. It is arranged in the form of some four or five papers given in each of nine sessions. These sessions are well arranged to give a clear account of the subject: they cover physiology (dealing particularly with movements of the alimentary tract), absorption, the young animal, the regulation of intake, microbiology, mineral metabolism, biochemistry (carbohydrate, nitrogen and fat metabolism) and metabolic disorders. International authorities, particularly from Australia and the United States, have contributed excellent summaries of their own particular area of interest, and each session is completed by a contribution from a discussant who places each part in context.

The proceedings have been presented in a most effective form and were clearly well edited. Phillipson was assisted by a group of colleagues authoritative in their particular scientific disciplines as applied to the study of the rumen and the ruminant. The proceedings are of the third international symposium dealing with this subject. They are held at intervals of five years and constitute a valuable series of volumes: a very high standard has been set in this volume which will be difficult to maintain in five years' time. The book constitutes an ideal source of reference for all students of the rumen whether they are undergraduates (agriculture or veterinary) or research workers. The subject, which has brought together so many individual scientific disciplines within an integrated whole, is fully described: its importance is readily apparent when it is recognized that ruminants yield 70 per cent of the world's meat protein and almost all milk and milk products.

D. LEWIS

\section{Arguments about Drift}

Debate about the Earth: Approach to Geophysics through Analysis of Continental Drift. By H. Takeuchi, S. Uyeda and $H$. Kanamori. Revised edition. Pp. 281. (Freeman, Cooper: San Francisco, 1970.)

THIs book is a very effective introduction to geophysics, using the controversy over continental drift as a theme. This "debate about the Earth" is still continuing today, although Wegener published his theory of drift as long ago as 1912, and the heat has by no means died down. The study of continental drift embraces all branches of geophysics, and the concept lends itself well to popular account. Just so with this book. The authors, all eminent scientists, have given a clear and fascinating presentation of the historical development of the hypotheses of drift, from early times to the now familiar ideas of plate tectonics.

There are nine chapters; the first two introduce the reader to Wegener and his work, and initiate the "debate", centering the argument on the problem of a feasible mechanism for drift. Chapters three and four discuss the Earth's magnetic field and the principles of rock magnetism. One of the clearest accounts that I have seen of the "dynamo theory" for the origin of the Earth's magnetic field is given in chapter three. It is these two, and the subsequent chapter, which set the tone of the book. It is a personalized account, with the excitement and doubts of the scientists involved left in. Chapter five deals with the palaeomagnetic evidence for drift, and exemplifies the healthy rivalry between different research groups-in this case Professor S. K. Runcorn's at Newcastle and that of Professor P. M. S. Blackett at the University of London. Chapter six discusses the temperature distribution within the Earth and also some arguments concerning the Earth's origin. Possible mechanisms for drift must be compatible with estimates of available energy, and this automatically leads on to a study of the birth of planets. This chapter shows the important link between cosmology and the earth sciences. Chapters seven and eight are about the evidence from the ocean floors; descriptions are given in chapter seven of the early bathymetric, magnetic and heatflow surveys over ocean ridges, and some remarks about the mantle convection theory. Chapter eight - the new chapter in this revised edition-is remarkable for its lucid account of transform faulting and seafloor spreading. Chapter nine is by way of summing up.

In all, I recommend this book to those with a non-specialist interest in geophysics although the specialist, too, would benefit from its scientific humour. It is neatly produced-the paperback edition using a bathymetric picture of the Atlantic ocean floor, by Heezen and Tharp, as a front cover design. The Japanese edition which, incidentally, grew from a television programme given by one of the authors, has been ably translated into English, with very few errors, by Mrs Keiko Kanamori.

\section{BRIAN W. DARRACOTT}

\section{Modelling Inorganic Molecules}

Models in Structural Inorganic Chemistry. By A. F. Wells. Pp. xi+186. (Clarendon: Oxford; Oxford University : London, October 1970.) 55s boards; 28s paper.

THIS unusual book by Professor Wells is quite unlike any conventional account of 